\title{
Spontaneous spinal epidural haemorrhage complicating transjugular intrahepatic portosystemic stent shunting
}

\author{
S McLellan, R de Silva, PA Sandercock, PC Hayes, J Dillon, D Redhead
}

\begin{abstract}
Summary
A patient with chronic liver disease and portal hypertension who developed acute spinal cord compression following transjugular intrahepatic portosystemic stent shunting is described. Radiological and pathological examinations revealed an epidural haematoma.
\end{abstract}

Keywords: transjugular intrahepatic portosystemic stent shunting, spinal epidural haemorrhage

Variceal haemorrhage is a common and lifethreatening complication in patients with cirrhosis and portal hypertension. Approximately $50 \%$ of patients die as a consequence of their first bleed, and the rate of recurrent bleeding remains high despite oral propranolol, injection sclerotherapy and band ligation. ${ }^{1}$ Non-emergency portosystemic shunt surgery is effective at preventing rebleeding but is still associated with appreciable peri-operative mortality and a high incidence of complicating post-operative hepatic encephalopathy. ${ }^{2,3}$ Transjugular intrahepatic portosystemic shunting (TIPSS) is a new technique used mainly for the treatment of and prevention of variceal haemorrhage. The attraction of TIPSS lies in its relative simplicity and low procedurerelated mortality $(1-2 \%) .{ }^{4}$ We report the case of a 59-year-old man who developed acute spinal cord compression due to an epidural haematoma following a variceal bleed treated with banding and TIPSS.

\section{Case report}

A 59-year-old man with known alcoholic cirrhosis presented to a district general hospital with his first episode of haematemesis and melaena. He had diet-controlled diabetes mellitus, hypertension and a previous history of duodenal ulceration (diagnosed on barium meal). There was no history of nonsteroidal anti-inflammatory drug ingestion and he had reportedly abstained from alcohol consumption for several months. His only medication was atenolol.

On physical examination he was haemodynamically stable and had stigmata of chronic liver disease. He was icteric, and had hepatosplenomegaly and ascites. There was melaena on per rectal examination.
Initial investigations were as follows (with normal values in parenthesis): urea $3.2 \mathrm{mmol} / 1$ (3.3-6.6), creatinine $55 \mu \mathrm{mol} / 1 \quad(70-110)$, bilirubin $84 \mu \mathrm{mol} / 1(3-16)$, alanine transaminase $64 \mathrm{IU} / 1$ (5-59), alkaline phosphatase $222 \mathrm{IU} / 1$ (136-330), albumin $23 \mathrm{~g} / \mathrm{l}$ (3550), haemoglobin $124 \mathrm{~g} / 1(120-180)$, platelets $41 \times 10^{9} / 1(150-400)$, prothrombin time ratio $1.5(0.9-1.2)$, activated partial thromboplastin time ratio $1.2(0.9-1.2)$.

He remained stable and underwent endoscopy the following day. $\mathrm{He}$ was found to have grade 3 oesophageal varices with no active bleeding, and no peptic ulceration. Treatment with lactulose and spironolactone was instituted, and he was referred to the regional hepatology centre. At the regional centre the endoscopy was repeated and two grade 3 oesophageal varices were banded. The patient's condition remained satisfactory and three days later a TIPSS procedure was undertaken to reduce the risk of rebleeding. During this procedure, just after expanding the parenchymal tract and immediately prior to insertion of the metal stent, the patient complained of pain between his scapulae. He was haemodynamically stable and did not have any neurological deficits. He was given extra sedation and the procedure was completed uneventfully. On returning to the ward he remained drowsy.

The following morning the patient complained of numbness and weakness in his legs. On physical examination he had a flaccid quadraparesis with loss of sensation below the nipple line. He was referred urgently for a neurological opinion. On admission to the neurology unit he was unable to move his legs. In his arms, he had preserved elbow and wrist flexion but not extension. All his tendon reflexes were absent and the plantar responses were mute. He had lost all sensation below the level of $\mathrm{C} 6$ and he had a palpable, distended bladder. Cranial nerve examination was normal. A magnetic resonance scan of the cervicothoracic region showed an hyperdense collection posterior to the spinal cord extending from the mid-cervical to the mid-thoracic levels (figure). This appearance in a man with an underlying coagulopathy was highly suggestive of a spinal epidural haemorrhage. Neurosurgical colleagues felt that in view of the severity and duration (at least $12 \mathrm{~h}$ ) of the neurological deficit, recovery of function was unlikely and that he should be managed conservatively. 


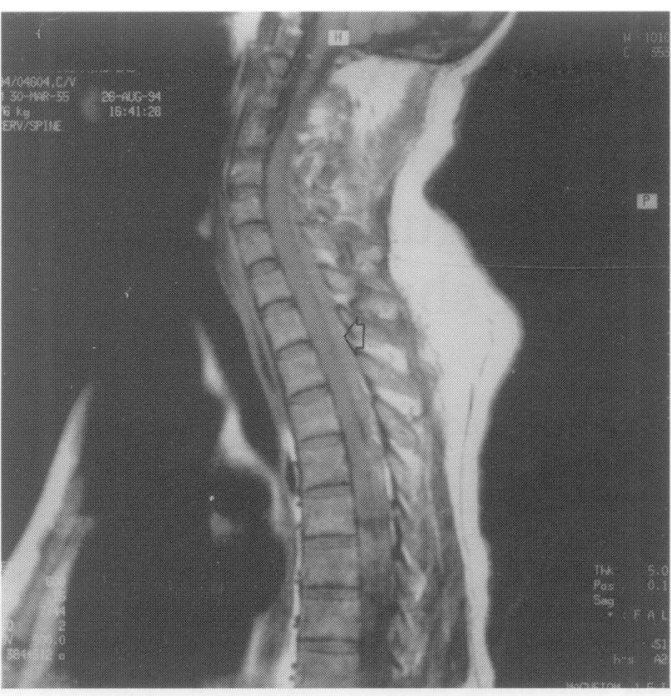

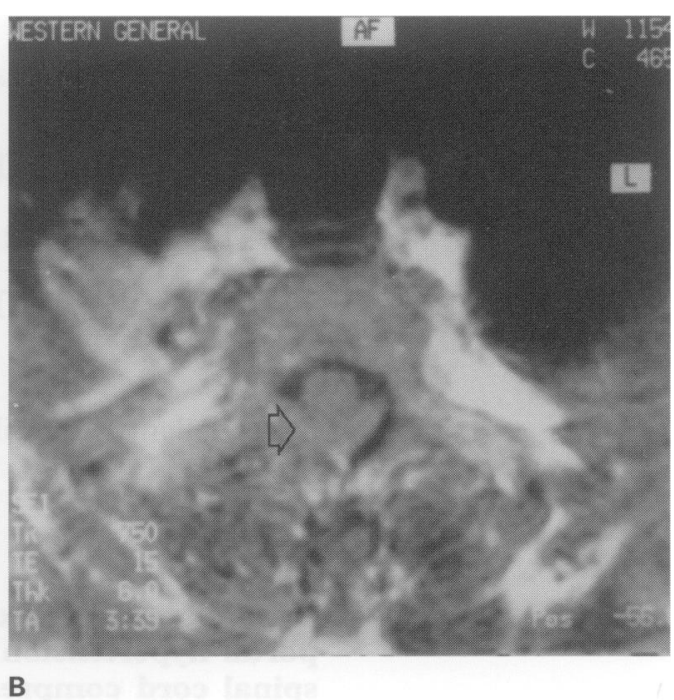

B

Figure Sagittal image of cervical and thoracic spinal cord (A) and transverse image of thoracic spinal cord (B) by T1-weighted magnetic resonance. The epidural collection of blood has been arrowed

He was given fresh frozen plasma in an attempt to correct his coagulopathy (prothrombin time ratio following transfer was 2.3) but this was complicated by left ventricular failure and had to be discontinued. Over the ensuing days he became encephalopathic, developed bronchopneumonia and disseminated intravascular coagulation supervened. He died three weeks after his initial presentation.

At autopsy he was found to have hepatocellular carcinoma on a background of macronodular cirrhosis. Dissection of the spinal cord revealed an extradural haematoma and haemorrhagic infarction within the lower cervical and upper thoracic regions. There were no spinal varices.

\section{Discussion}

To our knowledge, this is the first description of a spinal epidural haemorrhage following a TIPSS procedure. Spontaneous spinal epidural haemorrhage is rare. ${ }^{5-7}$ However it has been described following activities such as bending, sawing wood, sneezing, paroxysms of coughing or vomiting and straining at stool or micturition. A few cases have been associated with bleeding diatheses. ${ }^{8}$ In this particular case, the spinal epidural haematoma cannot unequivocally be attributed to the TIPSS procedure. However, it is conceivable that haemorrhage may have been precipitated by a sudden increase in the central venous pressure due either to straining with pain, or to the creation of the intrahepatic shunt; indeed, much of the

1 Fleig WE, Stange EF. Oesophageal varices: current therapy in 1989. Endoscopy 1989; 21: 89.

2 SpinaGP,SantambrogioR,OpocherE, etal.Distal splenorenal shunt versus endoscopic sclerotherapy in the prevention of variceal rebleeding. Ann Surg 1990; 211: $178-86$.

3 Harley HAJ, Morgan T, Redeker AG, et al. Results of a randomised trial of end to side portacaval shunt and distal splenorenal shunt in alcoholic liver disease and variceal bleeding. Gastroenterology 1986; 91: 802-9.

4 Jalan R, Redhead DN, Simpson KJ, Elton RA, Hayes PC. (TIPSS): long-term follow-up. $Q \mathcal{H}$ Med 1994; 87: 565-73.

\section{Learning point}

TIPSS is a relatively new procedure and continued vigilance is required until greater experience has been gained

reduction in the portal pressure gradient (portal pressure minus inferior vena cava or right atrial pressure) is due to a rise in the central venous pressure and not solely due to a reduction in portal pressure. In this particular case the portal pressure gradient fell from $28 \mathrm{mmHg}$ to $5 \mathrm{mmHg}$ following TIPSS. A raised central venous pressure in turn could have impaired dural venous return and oozing of blood may have accounted for the patient's complaint of back pain. The presence of a coagulopathy would also have contributed to the formation of the haematoma. This may have been an exceptional case but it highlights a possible danger of combined high portal venous pressure and coagulopathy during TIPSS. In view of this risk, any coagulopathy should be meticulously corrected prior to the procedure.

In conclusion, although TIPSS is a comparatively simple technique which is gaining acceptance in the management of acute variceal haemorrhage and rebleeding refractory to endoscopic treatment, it is still a relatively new procedure and continued vigilance is required until greater experience has been gained.

5 Kaplan LI, Denker PG. Acute non-traumatic spinal epidural haemorrhage. Am f Surg 1949;78: 356-61. 6 Lowry JJ. Spinal epidural haematomas. Experiences with 3 patients. F Neurosurg 1959; 16: 508-13.

7 Schultz EC, Johnson AC, Brown CA, Mosberg WH Jr. Paraplegia caused by spontaneous spinal epidural haemorrhage. F Neurosurg 1953; 10: 608-16.

8 Cube HM. Spinal extradural haemorrhage. $f$ Neurosurg 1962; 19: $171-2$. 